\title{
Breast cancer self-examination practice and associated factors among women reproductive age group in southeast Ethiopia
}

\author{
Abduljewad Hussen Mohammed \\ Madda Walabu University \\ Musa Kumbi Ketaro \\ Madda Walabu University \\ Abate Lette Wodera ( $\square$ abate.lette@yahoo.com ) \\ Casa di Cura La Maddalena SpA \\ Shemsu Nuriye Hajisso \\ Wolayta Sodo University
}

Research article

Keywords: Detecting breast cancer, reproductive age group women, breast self-examination practice, knowledge of breast self-examination.

Posted Date: December 23rd, 2019

DOI: https://doi.org/10.21203/rs.2.19436/v1

License: (c) (1) This work is licensed under a Creative Commons Attribution 4.0 International License. Read Full License 


\section{Abstract}

Background: Breast cancer is the most prevalent and the second cause of cancer deaths among women worldwide especially in developing country. It is considered as a progressive disease with a poor prognosis if detected late. Therefore, its early detection using breast self-examination plays a significant role in reducing morbidity and mortality related to breast cancer.

Objective: This study aims to evaluate breast self-examination practice and associated factors among women reproductive age group in southeast Ethiopia.

Methods: A community based cross sectional study was conducted on 836 reproductive age group women. Interviewer administered questionnaire was used for quantitative part of the study and supplemented qualitatively using focus group discussions. Data was interred into Epi-info version 3.5.3, and analysed using SPSS version 20. Bivariate and multivariable logistic regressions were done to examine the effect of explanatory variables to the outcome variable. Variables with P. value $<0.05$ during multivariable logistic regressions were considered as significantly associated with the dependent variable.

Result: Out of eight hundred thirty six total participants, $20.7 \%$ of them had ever heard about breast selfexamination practice. Also only $13.2 \%$ of the mothers had practiced breast self-examination. Maternal age, mother's level of education, and previous history of breast examination by health professionals were major predictors for breast self-examination practice.

Conclusion: This study reported lower prevalence of breast self-examination practice. Therefore, enhancing maternal education and coverage of breast examination by health professionals are essential to raise the odds of breast self- examination practice among women reproductive age group.

\section{Background}

Breast cancer (BC) is the most common form of cancer among women worldwide and attacks women in their most productive and reproductive years of life [1]. It is characterized by the uncontrolled growth of anomalous cells in the milk producing glands of the breast or in the ducts that provide milk to the nipples; and it arises in the breast tissue that is made up of glands for milk production, called lobules, and the ducts that link the lobules to the nipple [2, 5]. Breast cancer typically yields no symptoms when the tumor is small and most easily cured. Therefore, it is very essential for women to follow suggested screening rules for detecting $B C$ at an early stage. When $B C$ has developed to a size that can be felt, the most common physical sign is a painless lump or swelling even before the original breast tumor is large enough to be felt. Other common signs and symptoms include breast pain or heaviness, persistent changes to the breast (swelling, thickening, or redness of the breast's skin), and nipple abnormalities (spontaneous bloody discharge), erosion, inversion, or tenderness [1, 5]. 
Aside from being female, age is the most important factor affecting $\mathrm{BC}$ risk in women. The other risk factors for $\mathrm{BC}$ are inherited mutations in $\mathrm{BC}$ susceptibility genes, a personal or family history of $\mathrm{BC}$, high breast tissue density, and high dose radiation to the chest as a result of medical procedures [6], reproductive factors that increase risk (early start of menstrual periods and/or end later in life), not ever having children, prolonged use of oral contraceptives, and having child after age of thirty, some other factors that increase risk include being overweight or obese after menopause, use of menopausal hormone therapy (combined), physical inactivity, and consumption of alcohol [7].

The most imperative strategies for achieving early detection of $\mathrm{BC}$ are mammography and physical examination of the breasts by qualified health workers or clinical breast examination (CBE) and breast self-examination (BSE). Breast self-examination has been broadly recommended as a comparatively simple, non-offensive, non-harmful, and cost-free screening technique when comparing to other types of screening approaches for breast cancer. It is a technique established for the definite purpose of looking for cancer; a woman uses her hands to systematically examine her breasts and the immediate areas for unfamiliar lumps and shape changes. Usually done on a fixed monthly basis, the same technique is used each time, ensuring that all areas of the breast are sensed and checked thoroughly. The purpose is to screen for and discover BC as early as possible $[11,12]$.

Breast cancer is the most prevalent cancer specially in developing countries $[8,10]$. In Ethiopia, BC is typically a fatal disease with high morbidity and mortality [9], unlike the experience of the western world where BC is treatable and with lower mortality [26]. Ethiopia has set comprehensive BC prevention, diagnosis, and treatment interventions and available for women [27]. However, stigma towards cancer, poor knowledge of BC related to signs, symptoms and its treatability, and system overload continue to account for delays in reaching care [28]. Ethiopian women usually present for care at a late stage in the disease [9], where treatment is most ineffective, and while system-related barriers to care account for a portion of that delay, women's attitudes and lack of awareness of BC also account for a stalled initiation of action [29]. Therefore, this study was designed to identify the breast self-examination practice and major causes among reproductive age women in Bale zone, southeast Ethiopia.

\section{Methods}

\section{Study design, area and period}

A community based cross-sectional study was conducted from March to May, 2017 in Bale zone. The Bale zone has 20 districts. Robe town is the capital city of Bale zone which far 430 kilo meters from Addis Ababa, the capital city of Ethiopia.

\section{Sample size determination}

Single population proportion formula was used to determine the sample size for the quantitative data. Proportion of breast self-examination practiced 53.6\% [13], the desired precession $5 \%$ with $95 \%$ 
confidence level, design effect of 2 , and $10 \%$ non-response rate was considered and the final sample size calculated to be 841 .

For qualitative data six focus group discussions (FGD), two focus group discussions for each district, composing of 9 to 10 members in each group was conducted. Totally, 59 discussants were participated in the discussions.

\section{Sampling procedure}

A multi-stage sampling technique was used to select the study participants. In the first stage three districts were selected randomly. The kebeles in the selected districts were identified and stratified into urban and rural kebeles. The selected districts have seven urban and 70 rural kebeles. Then three kebeles from the seven urban (one from each district) and nine kebeles from 70 rural kebeles were selected by using lottery method. The selection of kebeles was depending on their distance from the capital town of the district, taking the hospital as a center. For the three districts, furthest kebeles in average were at the distance of $45 \mathrm{kms}$. From the total kebeles closest to the town, those were at about $15 \mathrm{kms}$, three kebeles; from the middle distant kebeles those were at the second $15 \mathrm{kms}$, three kebeles; and from the furthest (third $15 \mathrm{kms}$ ) also three kebeles were selected randomly. Lists of all households with eligible mothers were identified; finally, we used a sampling frame to pick the study participants using simple random sampling method.

For the qualitative data convenience sampling technique was used to select participants. From each selected districts, two groups of child-bearing age women, being that study population and not included in the quantitative study were participated in the focus group discussion.

\section{Data collection and data quality assurance}

For quantitative data collection, an interviewer administer structured and pre tested questionnaire was modified from different literatures according to the purpose of the study. Interview guide was used to conduct FGD for qualitative part of data collection, and tape recorder was also used [14-16]. The questionnaire and interview guide were originally prepared in English language then translated to the local language (affan Oromo), and translated back to English to check the consistency.

Quantitative data was collected using face to face interview method with twelve diploma nurses for data collectors and three supervisors were recruited and given two days training. The training of data collectors and supervisors mainly focused on issues such as data collection tools, field methods, inclusion-exclusion criteria and record keeping. The investigators coordinated the interview process, and reviewed the completed questionnaire on a daily basis to ensure the completeness and consistency of the data collected. The questionnaire was pre-tested on $5 \%$ of the sample outside the selected district for this study.

Each focus group discussion was conducted by two trained female diploma nurses; one did moderate the discussion and the other took notes and recorded tape. One gate keeper (non- health professional) for 
each FGD was assigned.

\section{Data Analysis}

The quantitative part of the data was entered into Epi-info, version 3.5.3, for data clearance and observation of data consistency and it was exported to SPSS version 20 for data analysis. First, descriptive statistics like frequency, percentages, mean and standard deviation were carried out to describe the data. Then, simple logistic regression analysis was done by taking each independent variable with dependent variable to examine the association between the two variables. On simple logistic regression analysis significant variables at $P$-value $\leq 0.25$ were retained for subsequent multivariable logistic regression. Strength of association was tested using adjusted odds ratio (AOR) and 95\% confidence interval $(\mathrm{Cl})$. The significance level considered for multivariable logistic regressions was $\mathrm{P}$ value $\leq 0.05$.

For qualitative data, tape recorded and transcribed qualitative data was organized in narrative forms in congruent with the respondents' own words and analysed under selected themes based on the question guide and summarized manually.

\section{Ethical consideration}

Administrative approval was obtained before conducting the study and ethical considerations was respected. Ethical clearance letter was obtained from Madda Walabu University ethical clearance committee. Official letter of collaboration was written to Bale zone administration, Ginnir, Sinana and Madda Walabu districts administrations to get formal permission. Informed consent was obtained from each interviewee and they were also given the choice to refuse to participate in the study.

\section{Results}

\section{Socio-demographic characteristics}

A total of 836 mothers completed the questionnaire making response rate $99.4 \%$, with the mean age of $31.09 \pm 7.34$ SD years. Forty five percent of the study participants were illiterate. The majority, $89.0 \%$ of the study participants were married. Ninety percent of women were house wives. Regarding husband's level of education, above half (52.5\%) of them finished primary school. The majority $55.4 \%$ of respondents had monthly income of below poverty line ( $<1311 \mathrm{~EB}$ ) that was $\$ 1.90$. The majority $56.8 \%$ of the study participants had television or radio. Regarding their residence area, the majority $74.9 \%$ was rural. Health centers or hospitals were very closer to $79.8 \%$ of the study participants which is about five kilometers or less and take maximum journey of 2 hours on foot (Table 1 ).

\section{Breast self-examination knowledge and practice}

The majority, $68.8 \%$ of the respondents had sufficient knowledge about breast cancer. Regarding sources of information: television and radio were the main sources, $56.6 \%$. Only $22.2 \%$ of participants knew the 
appropriate timing to perform BSE. The knowledge how BSE is performed was known to $58.7 \%$ of the study participants. The majority, $77.8 \%$ of the mothers responded that performing BSE is important. Above ninety percent of respondents have ever visited health facilities for any sickness. However, only $37.0 \%$ of the mothers were examined their breasts by health workers during the visit.

This finding was supported by qualitative study as a 19 years merchant mother reported, "...in our place there is no any awareness creating activities or education by doctors on breast problem: presence of the disease, its consequences, its sign and symptoms, and its risk factors, and an options of the treatment. We have heard some information from television and radio. Some of us are hearing even the presence of its management today from this discussion."

A 42 years civil servant also stated that, "... I heard my neighbour complaining of a breast disease; I heard also the disease is cancer. Many women have been suffered with breast disease, yet I have not seen breast disease on me.... When I was a child I had heard a woman of my neighbour died due to breast disease. Her breast was wounded, and she was referred and taken far out of this area to get better treatment in referral hospitals. Even though she had visited many hospitals, she died as the consequence of the disease."

During FDG a 25 years house wife also reported that, "...this breast disease is certainly present in its massive form; I have not experienced this disease on myself; it has hurt many women; and some people say it became "hola囚 on a woman; some say cancer, and some other say another thing. Even at the moment, there is a women with breast problem, she has birth recently, her breast has not have milk, she has severe breast ache."

In this study only $13.2 \%$ of the mothers performed BSE. The main reasons given by the mothers were lack of knowledge, $37.1 \%$ and feared of detecting abnormalities, 21.7\% (Figure 1). Those mothers who performed BSE had detected abnormalities in their breasts such as changes in contour $32.7 \%$, and lump in breast $26.4 \%$. The majority, $62.7 \%$ of the respondents who detected abnormalities in their breasts did consult health workers (Table 2).

During focus group discussion of mothers about BSE, six mothers stated that breast self-examination is unknown among us. For example, 23 years civil servant women reported that, "... we won't need to touch and examine our breast if we don't suspicion the problem. If it develops a problem, symptoms enforce us to touch and examine the breast. It is must to see some internally felt discomfort or externally observed sign and symptoms of disease. We don't know breast cancer. Therefore, we don't give focus to our breast. If we have previous problem, we check the improvement of that problem time to time. Unless and otherwise, we don't examine our breast..."

A 47 year house wife also stated, "... for example, at the moment I have pain of the breast, if all things, even children touch me, I feel pain on both breasts specially at the tip of it, before this time I haven't ever 
see such things. For this reason, I have started to touch and see my breast. If somebody has such problem that woman should touch and examine own breast, otherwise it doesn't need to touch..."

A 35 years health extension worker stated that, "... women know their breast or their body especially during a change. Breast pain is not simple, its pain is severe than other disease; therefore, it is easy to know breast problem on ourselves. However, women have seen this problem traditionally and some of them mostly seek traditional treatment because, they will not permit to expose their breast to health professionals if the disease is not sever. This thing makes the disease too fatal among our community..."

\section{Factors associated with breast self-examination practice}

Older women in the age range of 25-34, and 35-49 were more likely to practice BSE compared to those women in the age range of $15-24, \mathrm{AOR}=3.61(95 \% \mathrm{Cl}: 1.13,11.58)$, and $\mathrm{AOR}=9.35(95 \% \mathrm{Cl}: 2.31,37.85)$ respectively. Participants who have finished primary education, $A O R=3.88(95 \% \mathrm{Cl}: 1.26,11.98)$, and secondary and above, $\mathrm{AOR}=11.14(95 \% \mathrm{Cl}: 2.48,49.96)$ times more likely to practice BSE than illiterate mothers. In addition, participants who have ever breast examination history by health workers were more likely to practice BSE compared to those mothers who have not ever had breast examination by health workers, AOR=3.62 (95\%Cl: 1.15, 11.45) (Table 3).

\section{Discussion}

Breast self-examination (BSE) is an important and inexpensive method for screening and early detection of breast cancer [17]. This study showed $20.7 \%$ of the participants responded that they have ever heard about BSE. This result was very low compared to study conducted in Malaysia and Libya $[18,19]$. Mentioned sources of information on BSE for $56.6 \%$ of the study participants was television and radio together. These findings consistent with study conducted in Libya [18]. The present study showed that only $13.2 \%$ of the respondents have practiced BSE. This result much better than the study conducted in Zambia, 5\% and south India, 2.4\% [22, 23], and lower than the studies done in Malaysia, 48\%, Nigeria, $43.5 \%$, Ethiopia, $53.6 \%[13,19,25]$. This difference seems that because of HEP that help women on preventive aspect of health services. The main reasons mentioned by non- performers were lack of knowledge and fear of detection of abnormalities. This finding was similar with a study conducted in Iran [24].

This study showed that as age of the mother increases especially from twentieth to thirtieth, the practice of BSE has been increased. This is equivalent with a study reported from north Ethiopia [13], two studies conducted in Nigeria by Oladimeji et al., 2015 and Balogun and Owoaje, 2003 which revealed that current maternal age around second five of twentieth, the thirtieth and fortieth was significantly associated with BSE. This may be due to the fact that this age expected to be highly reproductive time, mothers' probability of giving attention to and seeking care for their breast, as the result increased contact to health facilities and health professionals become better than any other time. These may expose mothers to some information that can be obtained from health professionals and help them to practice BSE. 
Different studies showed that practice of BSE was determined by educational level of mothers. A study done in Libya [18], and another study done in Nigeria [25] reported that higher level of education was significantly associated with BSE practice. In consistent to these previously conducted studies, the finding of our study revealed that BSE was remarkably related to mothers' level of education. This is because educated mothers have a greater awareness of the existence of health care and benefited from by using such services. As education empowers women, they have greater confidence and capability to make decision to use modern health care services[26].

In this study previous history of breast examination by health professional was also another predictor for BSE practice. This result was consistent with the study conducted in northwest Ethiopia which indicated that health extension workers who previously examined their breast by health professional were a significant predictor of BSE practice. This could be due to the fact that if mothers realized or came to know how breast examination is done, the probability of continuing examination by selves seems high [14].

\section{Conclusion}

The study revealed low breast self-examination practice among reproductive age women comparing with another studies conducted in Ethiopia. The proportion of the respondents who had ever heard about breast self-examination was also low. Present maternal age, mothers' level of education and previous history of breast examination by health professional were found to have significant association with breast self- examination practice, so increasing maternal education and coverage of breast examination by health professionals are crucial to raise the odds of breast self- examination practice.

\section{Abbreviations}

BC Breast Cancer

BSE Breast Self-Examination

CBE Clinical Breast Examination

COR Crud Odds Ratio

FGD Focus Group Discussion

LMIC Low and Middle Income Countries

SPSS Statistical Package for Social Studies

SSA Sub-Saharan African Countries

WHO World Health Organization 


\section{Declarations}

\section{Ethics approval and consent to participate}

The study was done by interviewing the reproductive age mothers after an ethical consent was obtained from Madda Walabu University ethical clearance committee and individual verbal consent was obtained from the study participants. Regarding the minors, consent to participate was found from their parents on their behalf. This manuscript has never been submitted and deliberated for publication to any other journal.

\section{Consent for publication}

Not applicable.

\section{Availability of data and materials}

Data and materials will be available upon request. You can contact Mr. Abate Lette and Mr. Abduljewad Hussen if you want the data and materials at any time.

\section{Competing interests}

The authors have no any competing interest and all have agreed the manuscript for publication.

\section{Funding}

This study was funded by Madda Walabu University, Ethiopia. The University has supported this study financially and technically during the design of the study, collection, analysis, interpretation of data and in writing the manuscript.

\section{Authors' contributions}

The authors': AH, MK, AL and SN developed the concept, developed method, collect data and analyzed it and draft and edit the manuscript. All authors critically reviewed the manuscript, read and approved the final manuscript.

\section{Acknowledgments}

Authors are grateful to Madda Walabu University for supporting this study. We are also very grateful to mothers and data collectors for their cooperation to undertake this study.

\section{Authors' information}

$\mathrm{AH}$ is a lecturer at Madda Walabu University, MK is a lecturer and an academic and research coordinator at Madda Walabu University, AL is a lecturer at Madda Walabu University, and SN is a lecturer at Wolayita Sodo University. 


\section{References}

1. American Cancer Society. Breast Cancer Facts \& Figures. 2013-2014; Atlanta 2013;

2. American Cancer Society. Breast Cancer Facts and Figures, http://www.cancer.org/downloads /STT/CAFF2005BrFacspdf2005.pdf, accessed on 20 December 2016;2008;

3. Steward BW, Wild CP. World cancer report 2014, IARC Non-serial Publication: France 2014;

4. World Health Organization. Global strategy for women's, children's and adolescents' health.2015; 2016-2030.

5. National Breast Cancer Foundation. What is cancer? 2600 Network Blvd. Suite 300, Frisco, TX 75034, 972 -248-9200, /report/594611507/national-breast-cancer-foundation.pdf, accessed on 09/08/2017;2015;

6. Worsham, MJ, Raju, U, Lu, M . Risk factors for breast cancer from benign breast disease in a diverse population. Breast Cancer Res Treat. Nov; 2009; 118(1):1-7.

7. Ma, H, Hill, CK, Bernstein, L, Ursine, G. Low-dose medical radiation exposure and breast cancer risk in women under age 50 years overall and by estrogen and progesterone receptor status: results from a case-control and a case-case comparison. Breast Cancer Res Treat. 2008; 109(1):77-90.

8. Forouzanfar, M.H, Foreman, K.J. Delossantosetal, A.M 2011“Breast and cervical cancer in 187 countries between 1980 and 2010," he Lancet,vol.378,no.9801,pp.1461-1484,

9. Ferlay J, Shin, HR, Bray, F, Forman, D, Mathers, C \& Parkin DM. Estimates of Worldwide burden of cancer, GLOBOCAN. Int. J. Cancer. 2010; 127, 2893-2917.

10. International Agency for Research on Cancer (IARC). Latest world cancer statistics; 2013;

11. Kayode, F.O and T. M. O. G. Akande 2005, "Knowledge, attitude and practice of breast selfexamination among female secondary school teachers in Ilorin, Nigeria," Eurepan Journal of Scientiic Research, vol.10, no.3.

12. American Cancer Society. Breast awareness and breast self-exam. 2015;

13. Befikadu, $L$ and Teferi, G. Knowledge on breast cancer and its prevention among women household heads in Northern Ethiopia. Open Journal of Preventive Medicine. 2014; Vol.4,No.1,32-40.

14. Muluken, A, Gedefaw, A and Alemtsehay, M. Assessment of Factors Associated With Breast SelfExamination among Health Extension Workers in West Gojjam Zone, Northwest Ethiopia, Hindawi Publishing Corporation International Journal of Breast Cancer Volume, Article ID 814395, 6 pages http://dx.doi.org/10.1155/2013/81439515. Livingston JMC, Society M, Uni- B, Agents P. Work-related diseases and occupational injuries among workers in the. 2013;37-42.

15. Tesfay, $\mathrm{H}$, Hailemariam, $\mathrm{B}$, Desta, $\mathrm{H}$ and Haftu, B. Knowledge of breast cancer and its early detection measures among female students, in Mekelle University, Tigray region, Ethiopia. Science Journal of Clinical Medicine; 2014;3(4): 57-64, doi:10.11648/j.sjcm.20140304.11.

16. Rizwan, A, Saleem, Z and Sadeeqa, S. Effect of Family Income on Knowledge, Attitude and Practices Regarding Breast Cancer and its Screening Methods Amongst Women of Lahore, Pakistan, Journal 
of Applied Pharmaceutical Science; 2017; Vol. 7(08), pp. 028-033, DOI:

10.7324/JAPS.2017.70805, ISSN 2231-3354.

17. Tavafian, S.S, Hasani, L, Aghamolaei, T, Zare, S \& Gregory, D. Prediction of breast self- examination in a sample of Iranian women: an application of the Health. 2013;

18. Fatma, Y.MZ, Ahmed, A.T, Tahani R.H and Fayek, S, El-K. Females' knowledge attitude and practices about breast self-examination (BSE) and risk $f$ actors of breast cancer at Benghazi- Libya, Accessed on April 28/2017; 2013;

19. Sami, A.R, Kurubaran, G, Aied, M.A, Mohd, R.AM, Sharea, I, \& Saba, K . Exploration of Barriers to Breast-Self Examination among Urban Women in Shah Alam, Malaysia, Asian Pacific J Cancer Prev; 2012; 13, 1627-1632, DOI:http://dx.doi.org/10.7314/APJCP.2012.13.4.1627.

20. Redhwan, A, Yuri V.B \& Karim Al-J. Practice of Breast Self-Examination among Women inMalaysia,AsianPacificJCancerPrev:2012;13,3829-3833,DOI:http://dx.doi.org/10.7314/APJCP; 13.8.3829.22.

21. Ojong, I.N, E.EE, Uka, V.K and Edet, O.B. Breast cancer awareness and practice of breast selfexamination among women in Adiabo community in Odukpani local government area of Cross River State, Nigeria: 2016; Vol. 4, No. 1, DOI: 10.5430/cns.v4n1p50.

22. Mukupo, FC \& Mubita-Ngoma, CA 2007, Breast cancer knowledge and breast self-examination practice among rural and urban women in Zambia, African journal of nursing and midwifery: 2007; 9(1); ISSN 1682-5055; pp.50-58.

23. Anantha, L.S.D.K, Surendranath, B, and Vani, M.K 2014, Awareness and Practice of Breast SelfExamination among Women in South India, Inernational Journal of Current Microbiology and Applied Science, ISSN: 2319-7706 Volume 3 Number 1, pp. 391-394.

24. Parisa, $P$ \& Kandiah, M. Breast cancer know-ledge, perception and BSE practices among Iranian women. The International Medical Journal: 2005; 4, 17-24.

25. Oladimeji, KE, Tsoka-Gwegweni, JM, Igbodekwe, FC, Twomey, M, Akolo, C \& Balarabe, HS 2015, Knowledge and Beliefs of Breast Self-Examination and Breast Cancer among Market Women in Ibadan, South West, Nigeria, PLoS ONE 10(11): e0140904, doi:10.1371/journal.pone.0140904.

26. Coleman, M.P, Quaresma, M, \& Berrino F 2008, Cancer survival in five continents: a worldwide population-based study (CONCORD), The Lancet Oncology, vol. 9, no. 8, pp. 730-756.

27. Reeler, A.V, Sikora, K \& Solomon, B 2008, overcoming challenges of cancer treatment programmes in developing countries: a sustainable breast cancer initiative in Ethiopia," Clinical Oncology, vol. 20, no. 2, pp. 191-198.

28. De Ver Dye, T, Bogale, S \& Hobden, C 2011, A mixed-method assessment of beliefs and practice around breast cancer in Ethiopia: implications for public health programming and International Journal of Breast Cancer 5 cancer control," Global Public Health, vol. 6, no. 7, pp. 719731.

29. Andersen, R.S, Vedsted, P, Olesen, F, Bro, F \& Sondergaard, J 2009, Patient delay in cancer studies: a discussion of methods and measures," BMC Health Services Research, vol. 9, article 189. 


\section{Tables}

Table 1. Socio-demographic characteristics of the respondents in Bale zone, southeast Ethiopia, 2017

\begin{tabular}{|c|c|c|c|}
\hline Variable & & Number & Percentage \\
\hline \multirow[t]{3}{*}{ Maternal Age (Years) } & $15-24$ & 146 & 17.5 \\
\hline & $25-34$ & 424 & 50.7 \\
\hline & $35-49$ & 266 & 31.8 \\
\hline \multirow[t]{3}{*}{ Mother's Educational Level } & Illiterate & 376 & 45.0 \\
\hline & Primary School & 362 & 43.3 \\
\hline & Secondary School & 98 & 11.7 \\
\hline \multirow[t]{3}{*}{ Occupation } & House wife & 752 & 90.0 \\
\hline & Civil Servant & 62 & 7.4 \\
\hline & Merchant & 22 & 2.6 \\
\hline \multirow[t]{3}{*}{ Marital Status } & Married & 744 & 89.0 \\
\hline & Separated/Divorced & 57 & 6.8 \\
\hline & Widowed & 35 & 4.2 \\
\hline \multirow[t]{3}{*}{ Husband's Educational Level } & Illiterate & 278 & 33.3 \\
\hline & Primary School & 439 & 52.5 \\
\hline & Secondary School & 119 & 14.2 \\
\hline \multirow[t]{2}{*}{ Having TV or Radio } & No & 361 & 43.2 \\
\hline & Yes & 475 & 56.8 \\
\hline \multirow[t]{2}{*}{ Monthly Income } & Bellow 1311 & 463 & 55.4 \\
\hline & More than 1311 & 373 & 44.6 \\
\hline \multirow[t]{2}{*}{ Residence } & Rural & 210 & 74.9 \\
\hline & Urban & 626 & 25.1 \\
\hline \multirow[t]{2}{*}{ Distance of health facility } & $<=5 \mathrm{kms}$ & 667 & 79.8 \\
\hline & $>5 \mathrm{kms}$ & 169 & 20.2 \\
\hline
\end{tabular}


Table 2. Breast self-examination knowledge and practice in Bale zone, southeast Ethiopia, 2017

\begin{tabular}{|c|c|c|c|}
\hline Variables & Number & & \\
\hline \multirow[t]{2}{*}{ Have you heard about BSE } & No & 663 & 79.3 \\
\hline & Yes & 173 & 20.7 \\
\hline \multirow[t]{3}{*}{ *If yes, what is/are the sources? } & Health workers & 87 & 50.3 \\
\hline & TV or radio & 98 & 56.6 \\
\hline & Family or friends & 55 & 31.8 \\
\hline \multirow[t]{2}{*}{ Knowledge of breast cancer } & Not knowledgeable & 260 & 31.2 \\
\hline & Knowledgeable & 576 & 68.8 \\
\hline \multirow[t]{3}{*}{ Knowing how BSE is done } & One finger palpation & 73 & 8.7 \\
\hline & Palm and three finger palpation & 491 & 58.7 \\
\hline & Do not know how to do & 272 & 32.6 \\
\hline Previous HF visit for any & No & 76 & 9.1 \\
\hline sickness & Yes & 760 & 90.9 \\
\hline History of BE by HW & No & 527 & 63.0 \\
\hline during visiting of HF? & Yes & 309 & 37.0 \\
\hline \multicolumn{4}{|l|}{ Have you practiced BSE } \\
\hline & No & 726 & 86.4 \\
\hline & Yes & 110 & 13.2 \\
\hline Detected abnormalities during BSE $(n=110)$ & Contour & 36 & 32.7 \\
\hline \multirow[t]{5}{*}{$\operatorname{BSE}(n=110)$} & Lump in breast & 29 & 26.4 \\
\hline & Pain of breast & 26 & 23.6 \\
\hline & Itching of the breast & 12 & 10.9 \\
\hline & Tenderness & 9 & 8.2 \\
\hline & No any abnormal & 8 & 7.3 \\
\hline \multirow[t]{2}{*}{ Did you consult health workers $(n=102)$} & No & 38 & 37.3 \\
\hline & Yes & 64 & 62.7 \\
\hline Is it important to examine & Important & 650 & 77.8 \\
\hline your breast by yourself? & Not important & 186 & 22.2 \\
\hline Knowing appropriate time for & 2-3 days after monthly menstruation & 187 & 22.2 \\
\hline \multirow[t]{3}{*}{ performing BSE } & Monthly at any time & 144 & 17.5 \\
\hline & Few days before menstruation starts & 212 & 25.4 \\
\hline & Do not know specific time & 293 & 34.9 \\
\hline
\end{tabular}


Table 3. Factors associated with breast self-examination practice in Bale zone, southeast Ethiopia, 2017

Variables $\quad$ Ever performing BSE $\quad$ OR (95\%) CI

\begin{tabular}{|c|c|c|c|c|}
\hline & & & & \\
\hline & NO (\%) & Yes (\%) & COR & AOR \\
\hline \multicolumn{5}{|l|}{ Maternal age (in years) } \\
\hline $15-24$ & 138 & 14 & 1.0 & 1.0 \\
\hline $25-34$ & 418 & 45 & $1.61(0.76-3.41)$ & $3.61(1.13-11.58)$ \\
\hline $35-49$ & 170 & 51 & $3.44(1.26-9.39)$ & $9.35(2.31-37.85)$ \\
\hline \multicolumn{5}{|l|}{ Mother's level of education } \\
\hline Illiterate & 134 & 11 & 1.0 & 1.0 \\
\hline Primary school & 376 & 42 & $2.89(1.37-6.10)$ & $3.88(1.26-11.98)$ \\
\hline Secondary \& above & 216 & 57 & $5.68(2.23-14.51)$ & $11.14(2.48-49.96)$ \\
\hline
\end{tabular}

History of BE by health workers

\begin{tabular}{lcccc} 
No & 508 & 19 & 1.0 & 1.0 \\
\hline Yes & 218 & 91 & $5.11(2.36-11.06)$ & $3.62(1.15-11.45)$ \\
\hline
\end{tabular}

AOR: Adjusted for occupation, marital status, husband's educational level, having TV or radio, monthly income, residence, distance of health facility, knowledge of breast cancer, health education on BC, knowing how BSE is done, visiting health facility for any sickness

\section{Figures}

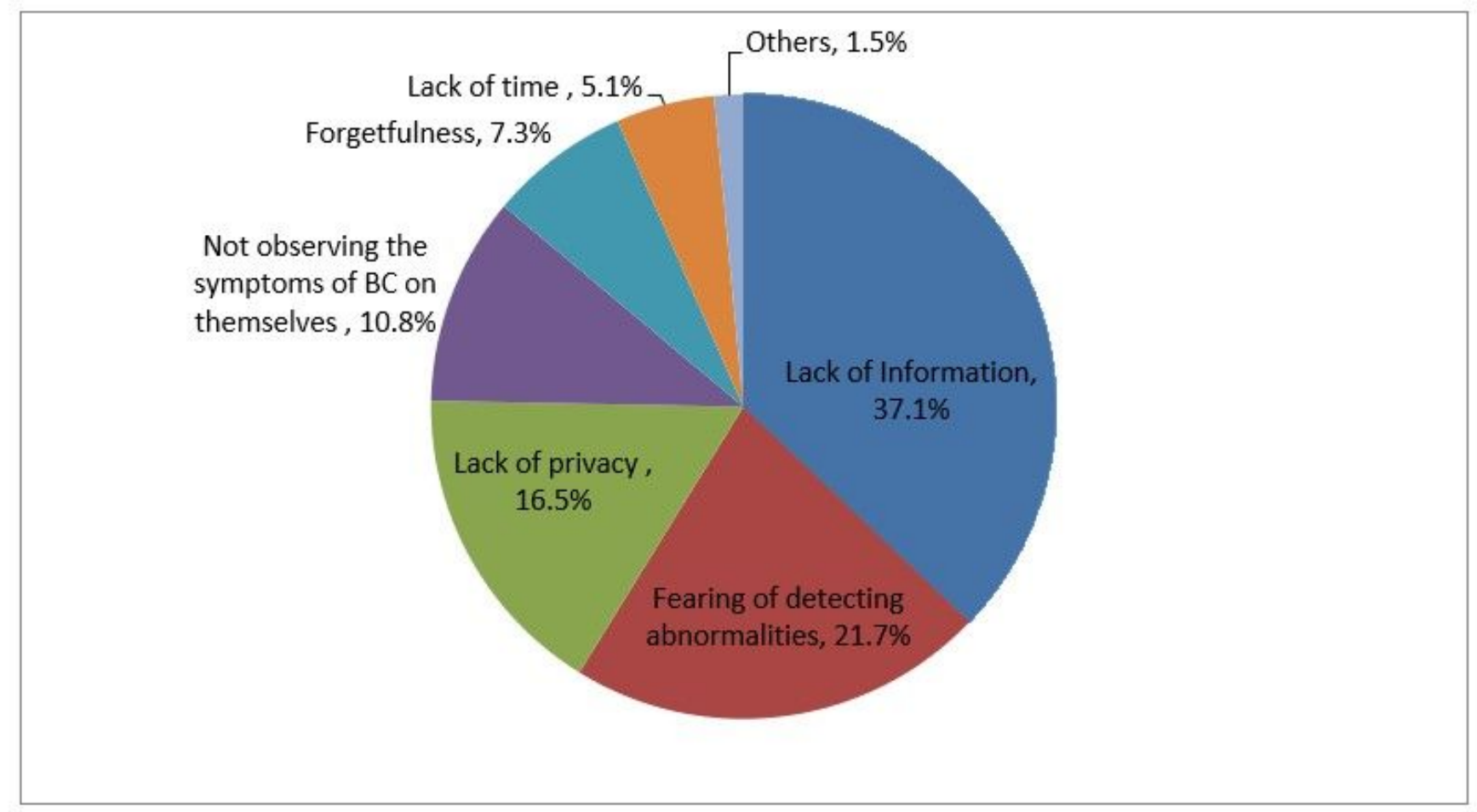




\section{Figure 1}

Reasons of non-performing BSE reported by the participants 